RAE-IC, Revista de la Asociación Española de Investigación de la Comunicación vol. 8, núm. 15 (2021), 357-387 ISSN 2341-2690

Recibido el 20 de mayo de 2020 DOI: https://doi.org/10.24137/raeic.8.15.16 Aceptado el 10 de noviembre de 2020

\title{
Las cámaras que nos pusiste van a volver. Redes sociales y denuncia de los abusos de las fuerzas de seguridad en las protestas de Chile 2019-2020
}

The cameras you put on us are going to come back. Social media and the reporting of abuses by law enforcement bodies in Chile's 2019-2020 protests

\author{
Godinez Galay, Francisco \\ Centro de Producciones Radiofónicas (CPR) \\ francisco@cpr.org.ar \\ Binder, Inés \\ Universidad Complutense de Madrid (UCM) \\ mbinder@ucm.es
}

Forma de citar este artículo:

Godinez Galay, F. y Binder, I. (2021). Las cámaras que nos pusiste van a volver. Redes sociales y denuncia de los abusos de las fuerzas de seguridad en las protestas de Chile 2019-2020. RAE-IC, Revista de la Asociación Española de Investigación de la Comunicación, 8(15), 357-387. https://doi.org/10.24137/raeic.8.15.16

\section{Resumen:}

La protesta social adopta nuevas características en la actualidad, mediada por el uso y la apropiación de tecnologías digitales. La ciudadanía hace uso de dispositivos como parte central de la mecánica de la manifestación, incorporando las estrategias digitales 
a su repertorio de acción colectiva. Uno de esos usos deja en evidencia la centralidad de las nuevas pantallas para la defensa de los Derechos Humanos, a través del registro, publicación y viralización en redes sociales digitales de los abusos de las fuerzas represivas y de los montajes de noticias falsas. Una capacidad ciudadana de vigilar al vigilador. El caso de las protestas iniciadas en octubre de 2019 en Chile, por su duración y características, resulta un caso paradigmático a partir del cual estudiar estas transformaciones.

Palabras clave: protesta social, redes sociales, vigilancia, ciberactivismo, pantallas.

\section{Abstract:}

Social protest takes on new characteristics today, mediated by the use and appropriation of digital technologies. Citizens make use of devices as a central part of the mechanics of the protest, incorporating digital strategies into their repertoire of collective action. One of these uses highlights the centrality of the new screens for the defense of Human Rights, through the recording, publication and spreading the abuses of repressive forces and the montage of fake news through social media. A citizen's capacity to watch over the watcher. Due to its duration and characteristics, the case of the protests that began in October 2019 in Chile is a paradigmatic case from which to study these transformations.

Keywords: social protest, social media, surveillance, cyber-activism, screens.

\section{INTRODUCCIÓN}

Ya vas a ver / las balas que nos tiraste van a volver

Canto de protesta

Las revueltas surgidas en América Latina durante 2019 nos ponen frente a nuevas formas de la protesta, muestran su poder de adaptación y las características que adoptan, propias de una época atravesada por las tecnologías digitales. En los últimos 
meses hemos asistido a una crisis de los sistemas políticos, del neoliberalismo, de los autoritarismos en varios países de la región.

En Ecuador, el alza del combustible generó una revuelta que incluyó participación del movimiento indígena, traslado de las funciones administrativas de la capital a Guayaquil y que puso en jaque al presidente Lenin Moreno que tuvo que derogar ese aumento. En Colombia, un paro nacional generó una ola de protestas que se prolongó por días en todo el país y que reclamó contra reformas económicas y laborales del gobierno de Iván Duque, junto con muertes de líderes sociales y los problemas relacionados al postconflicto interno. En Argentina un puñado de protestas más atomizadas fueron reprimidas y algunas lograron impedir reformas estructurales de corte neolibral durante el gobierno de Mauricio Macri (2015-2019). En Bolivia, luego de la renuncia obligada del presidente Evo Morales, sus partidarios salieron a las calles para resistir el autoritarismo y fueron víctimas de abusos y violencia. En Perú hubo protestas casi regularmente contra el gobierno, que resultaron en la renuncia de Pedro Pablo Kukczynski, la asunción de Martín Vizcarra y el cierre del Congreso durante un tiempo prolongado. En Puerto Rico una revuelta pidió la destitución de la gobernadora Wanda Vázquez por la corrupción, la mala gestión de la emergencia luego de un terremoto y por desproteger a los más pobres. En Haití, semanas de protestas exigiendo la renuncia del presidente Jovenel Moïse fueron respondidas con salvaje violencia. Hasta en Uruguay, una masiva marcha resistió un referéndum con el que se intentó instalar la idea de darle más poder al Ejército.

En todos los casos el denominador común fue la rabia contra el sistema, el hartazgo social, la desigualdad, la incapacidad de los gobiernos de ajustarse ágilmente a las demandas sociales y una respuesta cruelmente represiva. Pero, sin dudas, el caso de las protestas de Chile, fue excepcional: por la profundidad de la protesta, por ser Chile un país construido como caso de éxito del proyecto neoliberal, por el grado de violencia en la gestión estatal del conflicto, por la prolongada extensión temporal de las manifestaciones, y por la profundidad del cambio que se reivindica (Sehnbruch y Donoso, 2020, p. 52). Se trata del reclamo por un nuevo modelo económico y paradigma de organización social. 
La presente investigación busca aportar elementos que contribuyan a la comprensión del rol de las pantallas en los contextos de revuelta social. La primera parte está dedicada a hacer un repaso por la bibliografía sobre la intersección entre movimientos sociales y las Tecnologías de la Información y la Comunicación. En la segunda parte ahondaremos sobre los detalles metodológicos de la investigación, haciendo hincapié en la observación participante como metodología para el estudio de movimientos sociales. Luego aportaremos un análisis y reflexión sobre el rol de la imagen en la comunicación en contextos de protesta a partir de una serie de sucesos particulares en torno a las nuevas características del control y la gestión de la rabia social por parte de las fuerzas de seguridad del Estado, por un lado, y del activismo de las pantallas por parte de la ciudadanía, por el otro.

\section{CIBERACTIVISMO Y REPERTORIOS HÍBRIDOS DE ACCIÓN COLECTIVA}

La literatura sobre ciberactivismo, en especial las nuevas formas de protesta social habilitadas por las Tecnologías de la Información y la Comunicación, tiene un largo recorrido con más de dos décadas de desarrollo. Esta madurez teórica, sin embargo, no se traduce en posturas homogéneas respecto al impacto que la introducción de estos nuevos medios tiene sobre las formas de organización, la canalización de los reclamos o su efectividad. En un primer momento la literatura adoptó un abordaje más optimista poniendo el foco sobre las multitudes inteligentes (Rheingold, 2002), la organización horizontal habilitada por las TIC (Shirky, 2008) y la aparición de nodos autónomos y altamente conectados (Kelly, 1998, en Rheingold, 2002), o la conformación de una nueva esfera pública conectada que disputaba el poder de agenda setting a los medios tradicionales (Benkler, 2006). Pero la producción científica comenzó a poner en valor nuevamente las prácticas de política prefigurativa (Boggs, 1977 en Yates, 2005) y las competencias y la experiencia organizativa de las y los activistas como elemento central que configuraba el uso que los movimientos sociales hacían de las TIC (Garret y Edwards, 2007; Mosca, 2008; Tilly y Wood, 2010; Fleyer Fominaya, 2014). Castells (2012) incluye a la ecuación la centralidad del espacio urbano para la configuración de protestas como el 15M, Occupy o, en este caso, las protestas de Chile de 2019 cuyo epicentro fue la Plaza Dignidad, bautizada así por los manifestantes. Se conforma un espacio público 
híbrido que vincula "el poder de lo digital -crear y difundir información en red-con el poder del espacio geográfico (...)" (Jurgenson, 2012).

En los últimos diez años, y sobre todo a partir de las filtraciones de Edward Snowden (2013) un sector crítico de intelectuales ha denunciado la vigilancia masiva (Morozov, 2011; Zuboff, 2018), la polarización del discurso público (Pariser, 2011) o los sesgos algorítmicos (O’Neil, 2016; Noble, 2018), como características estructurales del modelo de desarrollo tecnológico contemporáneo.

Sin embargo, lo que no puede negarse -aunque sí pueden discutirse sus alcances- es que los dispositivos tecnológicos y las conexiones móviles se volvieron cada vez más accesibles suprimiéndose, o al menos reduciéndose, las barreras tecnológicas para la difusión de mensajes masivos. La penetración de teléfonos celulares en Chile es la más alta de la región (GSMA, 2019), con 134,5 líneas por cada 100 habitantes y un escenario de conectividad en el que "del total de accesos a Internet, el 84,6\% son móviles y del total de accesos móviles, por su parte, un 94,1\% corresponde a navegación por smartphones" (Subtel, 2020). En el contexto de las protestas, el destinatario de los teléfonos celulares, construido como un consumidor, es capaz de elaborar estrategias para evadir esa determinación y transformarse en un ciudadano que reconvierte al celular en una herramienta útil para otros fines que los previstos por el mercado. En palabras de De Certau (1996, p. XLII), "[I]o cotidiano se inventa con mil maneras de cazar furtivamente". El espacio público es reapropiado y ensanchado hacia el espacio cibernético que también es reapropiado o, al menos, disputado.

El estudio sobre el rol de los teléfonos celulares en las protestas ciudadanas ha ganado terreno en las investigaciones sobre nuevos movimientos sociales (Rheingold, 2008). Originalmente se estudió el poder de los mensajes de texto para combatir la desinformación y convocar a protestas, con impactos significativos en "Ghana, Hungría, Italia, Kenia, Corea del Sur, Kuwait, Filipinas, Sierra Leona, España, y Estados Unidos" (Rheingold, 2008, p. 226). Los teléfonos celulares se fueron complejizando y los repertorios de protesta también. 
Para el movimiento de Indignados de España la proliferación de los celulares "ha abierto innumerables posibilidades para la hibridación del espacio físico y digital" a través de plataformas como Twitter y el streaming online (Monterde y Pastill, 2014, p. 13). En China, además de facilitar el intercambio rápido de información, "la relación interpersonal mediada por el teléfono móvil actúa como un mecanismo fundamental de movilización al afectar a la decisión de la gente de participar en protestas" (Liu, 2015, p. 14). Aunque el optimismo se matiza en el caso de África donde "[l]os teléfonos móviles son, en efecto, un instrumento para la movilización política, pero esto ocurre en períodos de recesión económica cuando surgen motivos de queja o el costo de oportunidad de la participación en las protestas disminuye" (Mancorda y Tesei, 2020, p. 564).

Es decir, el análisis del rol de los teléfonos celulares debe entenderse en una tensión entre las oportunidades y las limitaciones para la manifestación masiva. En primer lugar, Neumayer y Stalkd (2014) nos animan a superar los análisis instrumentales -que en algún punto, alertan, tiente a la fetichización de los celulares- y tender al estudio del "uso de la comunicación móvil y el repertorio de acciones de protesta a través del dispositivo móvil, incluyendo las relaciones de poder que los activistas tratan de desafiar" (p. 129). Las autoras entienden que: "[e]l repertorio de tácticas de comunicación móvil para suministrar información en las acciones callejeras se amplía con el teléfono inteligente, lo que permite la comunicación más allá de las redes personales, así como el intercambio de expresiones visuales más poderosas de opresión e injusticia" (Neumayer y Stalkd, 2014, p. 129).

\section{APUNTES METODOLÓGICOS}

Siguiendo a Neumayer y Stalkd (2014) trabajamos con la hipótesis de que la posibilidad de que personas anónimas -en el sentido de que no son personajes que gocen de visibilidad y reconocimiento públicos- registren y publiquen en tiempo real los eventos de protesta es un factor que favorece y amplía el alcance de la circulación de los reclamos y de las denuncias de violaciones a los Derechos Humanos por parte de las 
fuerzas de seguridad. Consideramos que las protestas de Chile que comenzaron en octubre de 2019 representan un caso paradigmático en este sentido.

La presente investigación adopta un abordaje cualitativo desde una perspectiva de pluralismo metodológico, tendencia predominante en el campo de estudio de los movimientos sociales (Della Porta, 2014). En primer lugar, se optó por la observación participante en varias de las jornadas de protesta que se sucedieron en Santiago de Chile, entre diciembre de 2019 y febrero de 2020. La observación participante ha ganado popularidad en el estudio de los movimientos sociales en las últimas dos décadas gracias a que "[a]l experimentar las movilizaciones, los investigadores han dado algunos de los pasos más importantes en nuestra comprensión de lo que son los movimientos sociales" (Balsiger y Lambelet, 2014, p. 144). La observación participante nos permite recolectar información de primera mano para ponerla en conversación con la literatura existente. escalar la observación gracias a un profundo conocimiento de las prácticas estudiadas, $y$, experimentar, en el sentido de "tener la experiencia", entender el fenómeno estudiado desde la perspectiva de los sujetos (Balsiger y Lambelet, 2014, pp. 145-146).

Asimismo, durante las jornadas de protesta también se procedió a conformar un registro fotográfico propio que retrata escenarios y momentos clave de las movilizaciones, así como manifestaciones pictóricas realizadas por los propios manifestantes -en forma de grafitis, carteles, afiches, banderas, e intervenciones gráficas en el espacio público de todo tipo-que fueron incluidas en el corpus de discursos a ser analizados.

Se incorporaron al análisis, también, discursos identificados a través del rastreo documental en redes sociales, principalmente de dos cuentas dedicadas a cubrir las manifestaciones en distintos soportes -texto, imágenes, registros audiovisuales, etc.-. Por un lado, la cuenta de Twitter @piensaprensa, que se define como “chilenos, autogestionados, independientes, comprometidos con la verdad, resistencia mapuche y los Derechos Humanos"; y, por el otro, la cuenta @archivandochile, que funciona como "respaldo colectivo de fotos y videos de las protestas". Esta última cuenta con un grupo de Telegram donde las personas que participan de las protestan podían enviar sus registros para ser publicados en la cuenta. A partir de estas fuentes, y con las técnicas 
de la bola de nieve, se alimentó el corpus con tuits ciudadanos de denuncia de violaciones de derechos humanos por parte de las fuerzas de seguridad del Estado durante las protestas.

\section{4. "EVADIR, NO PAGAR, OTRA FORMA DE LUCHAR": ANTECEDENTES Y CONTEXTO DE LAS PROTESTAS}

El 18 de octubre de 2019 el metro de Santiago de Chile anunció un aumento en el precio del boleto de metro. Los estudiantes secundarios comenzaron a pasar los molinetes sin pagar y a convocar a hacer lo mismo - "evadir" el pago del pasaje - al resto de la ciudadanía. Pronto esta evasión se vinculó simbólicamente con diferentes evasiones de impuestos y responsabilidades que empresarios y políticos venían haciendo desde hacía tiempo, por lo cual el contraste de desigualdad se hizo rápidamente evidente y se fijó como núcleo del reclamo (Atria, 2019). "Evadir / no pagar / otra forma de luchar" fue el cántico que se cristalizó como un himno (Vargas, 2019). Pero lo que fue fundamental fue la viralización de la actitud de los jóvenes a partir de la difusión de imágenes en las redes sociales. Las pantallas, entonces, aparecen desde el comienzo como un factor fundamental para la construcción del reclamo.

Las protestas fueron incontrolables para la policía. La difusión de los hechos también. Pronto, los que había comenzado como un reclamo ante el aumento del transporte público derivó en una oleada de ataques incendiarios a diferentes lugares simbólicos del modelo neoliberal: supermercados, bancos, el Metro. El modelo chileno, construido de cara a la opinión pública internacional como caso de éxito del proyecto neoliberal, conocido como "Milagro de Chile" (Suárez Jaramillo, 2019) escondía grandes niveles de desigualdad. Chile se encuentra entre los diez países más desiguales del mundo en términos de desigualdad de ingresos (Parra, 2018; Sehnbruch y Donoso, 2020).

La reacción del movimiento estudiantil ante el aumento de 30 pesos en el pasaje del metro detonó la manifestación pública de un descontento estructural latente. Pronto la ciudadanía salió a las calles a reclamar por las distintas formas de abuso del sistema económico y político chileno. La consigna "No son 30 pesos, son 30 años" reflejaba que no se trataba de un hecho puntual sino que la salida de la dictadura en 1990 no había 
sido condición suficiente para generar condiciones de vida digna (Salazar Vergara, 2019). Las bases del sistema económico neoliberal implantado por el dictador Augusto Pinochet no habían sido corregidas por la democracia, ni por los gobiernos de centro izquierda ni por los de la derecha.

La ciudadanía se volcó masivamente a las calles para reclamar por diferentes problemas estructurales: el sistema educativo expulsivo, elitista y caro; la salud precaria para quien no tiene dinero; el sistema de pensiones privatizado, erosiona toda posibilidad de vivir dignamente la vejez (Sehnbruch y Donoso, 2020, p. 54). La evolución de los reclamos sufrió un doble movimiento. Por un lado fueron diversificándose y multiplicándose: se incorporaron reclamos por el medio ambiente, el acceso al agua, los derechos de la infancia, la desocupación, la pobreza, el alto costo de vida, la privatización de los servicios públicos, las reivindicaciones feministas y de las disidencias sexuales y de género. Pero, al mismo tiempo, fueron condensándose en un pedido clave de la democracia chilena: una nueva Constitución (Sehnbruch y Donoso, 2020, p. 53). La Constitución de Chile fue diseñada por la dictadura militar de Pinochet $y$, además de tener una visión autoritaria y vetusta, se concibió como "cárcel de la democracia" (Gargarella, 2019). Por ejemplo, impone los dos tercios de los votos para algunas disposiciones legislativas, con lo cual una minoría puede obstaculizar transformaciones.

El proceso actual de manifestaciones tiene antecedentes. Por un lado, la llamada Revolución Pingüina de 2006, cuando estudiantes secundarios -primera generación de nacidos en democracia- reclamaron contra la desigualdad del sistema educativo (Bellei, Contreras, Valenzuela, 2010). Casi cinco años más tarde, cuando esa misma generación de jóvenes se convirtieron en universitarios, tuvieron lugar las protestas de 2011 por una reforma universitaria (Mayol Miranda y Azócar Rosenkranz, 2011). Así, los jóvenes son una vez más quienes detonan y asumen el protagonismo de las protestas. La diferencia, en este caso, es que las protestas de 2019 pusieron sobre la mesa demandas transversales arraigadas en la mayoría de la sociedad chilena. 
El Estado respondió a estas protestas con violencia. Elocuente es la cantidad de casos de mutilados oculares por disparos al rostro, el uso de perdigones de goma, ${ }^{1}$ la gran cantidad de violaciones y abusos sexuales a detenidos y detenidas (Ravanal y Marfn, 2020). También fueron habituales los casos de golpizas por parte de Carabineros, amedrentamientos, abusos, atropellos con vehículos policiales, las acciones de agentes sin identificación y bajo el efecto de estupefacientes, burlas a víctimas y familiares, invasiones de tipo copamiento territorial en algunas poblaciones de bajos recursos y robos (El Siglo, 2020). Son esos tipos de casos los que han trascendido gracias a la existencia de documentos como filmaciones, fotografías y audios, pero que no son producidos por los medios masivos de comunicación.

Las protestas iniciadas en octubre de 2019 se prolongaron por más de seis meses. Las manifestaciones convocadas en el espacio público sólo fueron suspendidas por la crisis de la COVID-19, aunque las reivindicaciones siguieron pendientes y las redes sociales mantuvieron despierto el reclamo. Al cierre de la presente investigación, las protestas presenciales se reactivaron logrando la realización de un plebiscito para que la ciudadanía decidiera si se debía redactar una nueva Constitución. La opción por la reforma ganó de manera contundente con un $78 \%$.

\section{PROTESTA SOCIAL Y EL ECOSISTEMA DE PANTALLAS MÚLTIPLES}

Tal y como describen Sehnbruch y Donoso (2020) una de las características de las protestas de Chile fue el grado de brutalidad policial. Carabineros fue "(...) brutal en sus métodos para contener o suprimir las manifestaciones, las cuales fueron generalmente pacíficas". La capacidad ciudadana de registrar y compartir fotografías y videos en tiempo real fue clave a la hora de dar visibilidad a los más de 1500 casos de violaciones de derechos humanos (Instituto Nacional de Derechos Humanos, 2020).

Exploraremos tres dispositivos que habilitan prácticas de contrainformación de denuncia de abusos y violaciones de Derechos Humanos por parte del cuerpo

\footnotetext{
${ }^{1}$ Según el análisis del Departamento de Ingeniería Civil Mecánica de la Facultad de Ciencias Físicas y Matemáticas de la Universidad de Chile, los proyectiles apenas tenían un $20 \%$ de goma y un $80 \%$ de metales y otros elementos distintos a la goma. Para ver el informe completo: http://dimec.uchile.cl/web/2019/11/balines-usados-por-carabineros-estan-compuestos-en-un-por-80-metalesy-otros-elementos-distintos-a-la-goma/
} 
Carabineros de Chile, y que ponen en jaque al discurso dominante de los medios masivos de comunicación y de las instituciones interesadas en mantener el status quo. Estos son: la difusión de videos de circuitos cerrados de videovigilancia; las filmaciones y fotos de celulares durante las protestas; y los espacios públicos híbridos, en los que las expresiones artísticas como afiches, stenciles, gratifis y murales, traspasan el margen en el que están inscritos a través de su reproducción digital en redes sociales.

\subsection{CIRCUITOS CERRADOS DE VIDEOVIGILANCIA: EL VIGILANTE VIGILADO}

La presencia de cámaras de seguridad es una realidad en todo el mundo. Las crecientes demandas por seguridad en un mundo cuyo capitalismo empuja a consumir y que mide el estatus por las posesiones materiales, a la vez que margina a grandes cantidades de población de las posibilidades de desarrollo, vida digna y felicidad, han dado lugar a que una de las respuestas, junto con el punitivismo, sea la del control:

Las antiguas sociedades de soberanía operaban con máquinas simples, palancas, poleas, relojes; las sociedades disciplinarias posteriores se equiparon con máquinas energéticas, con el riesgo pasivo de la entropía y el riesgo activo del sabotaje; las sociedades de control actúan mediante máquinas de un tercer tipo, máquinas informáticas y ordenadores cuyo riesgo pasivo son las interferencias y cuyo riesgo activo son la piratería y la inoculación de virus. No es solamente una evolución tecnológica, es una profunda mutación del capitalismo. (Deleuze, 2006, párr.7)

Las cámaras de seguridad aparecen como un síntoma de la sociedad de control. Habitar la vía pública es ser observado y registrado. Las vemos en los bancos, pero también en otros comercios, en los pórticos de los edificios, clubes, escuelas, en domicilios particulares. Incluso en los postes de luz, puestas por los municipios. Podemos decir que la cámara de seguridad forma parte del paisaje de una ciudad. Hay en ellas una amenaza de control constante, bajo la excusa de la persecución del delito. Pero también han servido para controlar al controlador: en Chile, se han utilizado filmaciones de estas cámaras para demostrar flagrantes violaciones a Derechos Humanos por parte de las fuerzas policiales. 
El 29 de enero de 2020 en la comuna de Puente Alto, carabineros golpearon salvajemente a un ciudadano. La golpiza fue filmada por una cámara de seguridad y trascendió a la esfera pública. Allí se ve a siete uniformados que se bajan del auto oficial, agreden al transeúnte en la vereda con palazos y patadas en la cabeza, lo abandonan y huyen. Es decir, no le pegan para reducirlo porque está indefenso. Tampoco lo abordan por estar cometiendo un delito, porque de hecho no se lo llevan detenido. Ese video, entonces, ha demostrado un abuso. El suceso se dio luego de una protesta en la que había participado el joven agredido.

Imagen 1. Captura de pantalla del vídeo

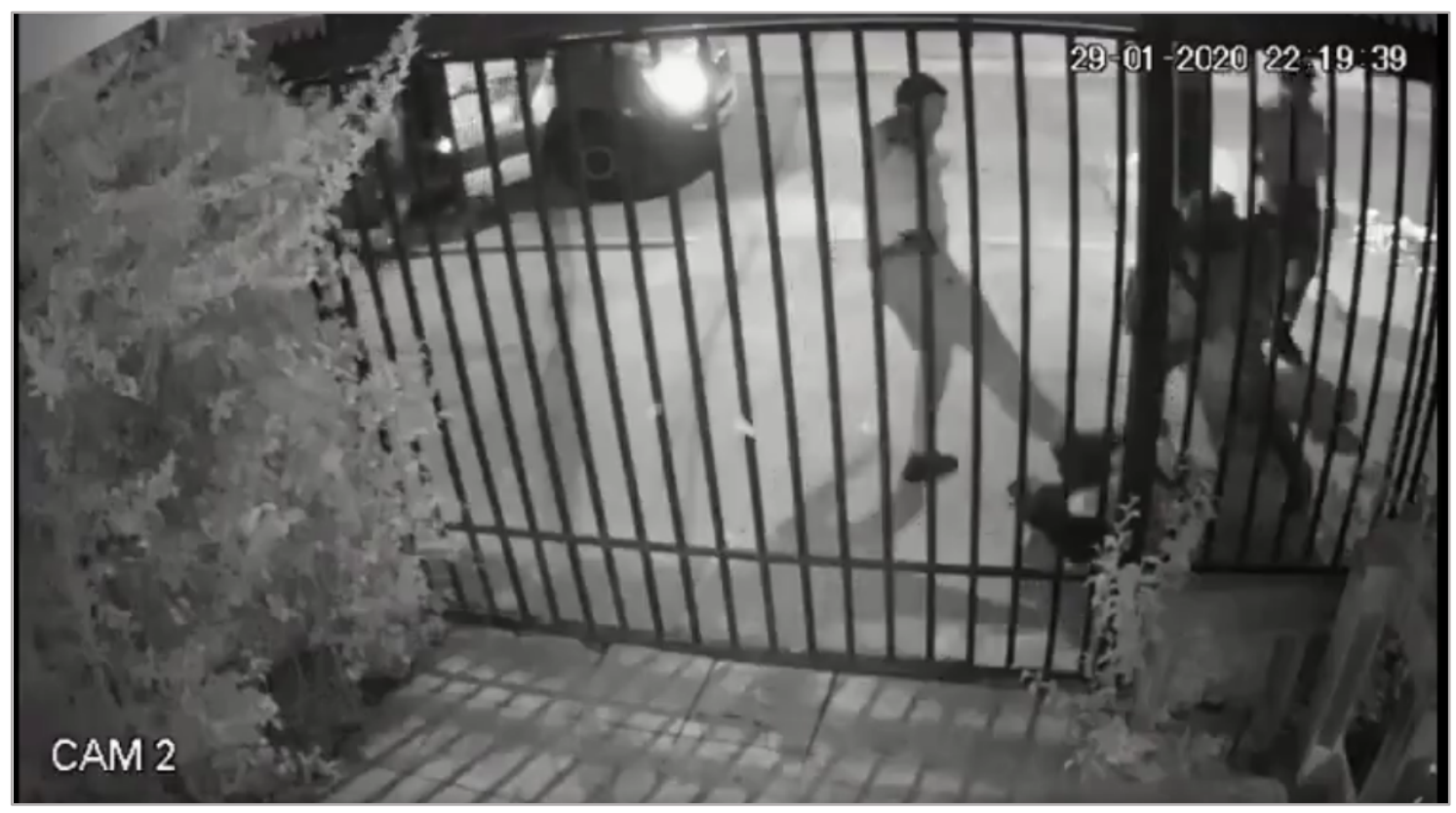

Fuente: https://twitter.com/PiensaPrensa/status/1223817124784869376

La acción ilegal de Carabineros ya no goza de la total impunidad porque hay cámaras observando. Esas mismas cámaras instaladas para ayudar a la persecución del delito, que se vuelven contra los propios controladores y brindan transparencia y algo de justicia a la ciudadanía. Terminan teniendo un uso no previsto por quienes idearon plagar las ciudades de cámaras de seguridad. "La cultura digital se parece mucho a un proceso civilizador, que trae nuevas posibilidades, pero también efectos secundarios imprevisibles y a veces inquietantes, o incluso peligrosos." (Doueihi, 2010, p. 22). 
Imagen 2. Cartel aviso en la vía pública, Comuna de Santiago Centro, Santiago de Chile

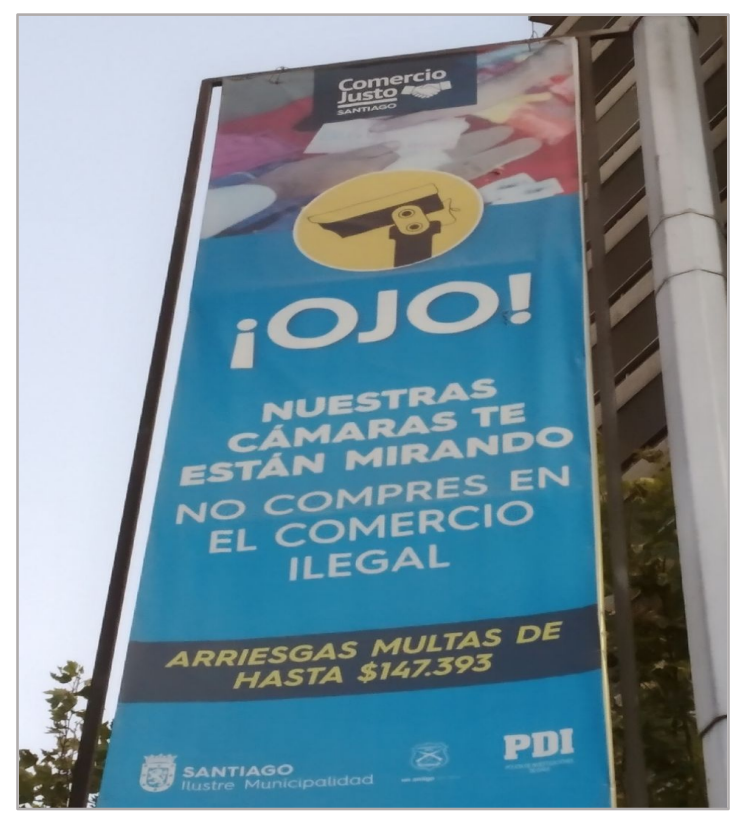

Fuente: Francisco Godinez Galay

\subsection{DISPOSITIVOS MÓVILES PARA LA DIFUSIÓN Y DENUNCIA CIUDADANA DISTRIBUIDA}

El teléfono celular se ha convertido en un objeto habitual, adherido al cuerpo. En el contexto de las protestas se ha convertido en un elemento de primera necesidad. Los celulares sirven para registrar todo el mal accionar de las fuerzas represivas y exponerlas en la arena pública. Hay una apropiación y resignificación de la tecnología por parte de los usuarios/ciudadanos.

Si existen los primera línea, manifestantes que resisten la violencia policial para garantizar que las marchas se realicen, y las brigadas de asistencia, profesionales de la salud que realizan trabajos de primeros auxilios en puestos improvisados o de forma móvil para asistir a manifestantes, (Cattaneo, 2020) puede existir algo como una segunda línea: manifestantes que con celular en mano, y en algunos casos comunicadores con equipos más sofisticados, apoyan a la primera linea a la vez que registran los sucesos para en algunos casos publicarlos en tiempo real. Una suerte de manifestantes-comunicadores propia de la tradición de la comunicación alternativa: 
En procesos alternativo-participativos los propios interesados hacen los mensajes. (...) Hay una elaboración espontánea según las necesidades, que se va perfeccionando a medida que aumentan la organización de los participantes y la experiencia en la confrontación con la propia realidad. (Prieto Castillo; 1984, p. 13).

Entonces, la escena de la protesta y la represión tiene diferentes actores, espacios asignados y una coreografía: los primera línea llevan pocas cosas, algunos escudos caseros, se protegen el rostro (de las filmaciones oficiales y de los gases) y cargan bidones con un líquido para neutralizar las bombas lacrimógenas; las brigadas de asistencia se identifican como personal de salud y se protegen con escudos con cruces rojas. La segunda línea lleva un celular en una mano y un rociador de agua con bicarbonato en la otra: protestan, asisten y registran. Todos van con máscaras antigas y muchos con antiparras.

Así como las protestas iniciaron en 2006 con las primeras generaciones de jóvenes nacidos en democracia, también son los jóvenes los que hoy pueblan mayoritariamente las marchas, que son nativos digitales y tienen al celular como algo adherido a su experiencia. Esto sucede en una forma que no es comprendida o que al menos toma por sorpresa a los altos mandos policiales, formados bajo otra opacidad y sin ese nivel de monitoreo ciudadano.

En el caso de Chile, la posibilidad que cada ciudadano tiene de registrar con su pequeña herramienta, ha modificado el curso de las protestas y evitado que los abusos fueran ocultados. Los teléfonos celulares y un medio como las redes sociales están teniendo usos creativos, impulsivos y no previstos por parte de los manifestantes que habitan y utilizan los recursos que la misma cultura digital les provee: "El entorno digital es primero, y antes que nada, una cultura del cambio veloz y de la adaptabilidad: es un fenómeno cultural impulsado por las adaptaciones sociales de innovaciones tecnológicas." (Doueihi, 2010, p. 17).

Hay un activismo que está utilizando las tecnologías de formas creativas para incidir con una agenda propia, opacada por la agenda de los medios masivos de comunicación. Un “activismo 2.0" (Fernández Prados, 2012) porque se vale de los territorios digitales para 
organizarse, convocarse, comunicarse, resistir y desbaratar montajes y fake news: "El uso disruptivo de tecnología también es una forma de resistencia cultural" (Binder, 2019, p. 214). Un activismo que es ciberactivismo porque utiliza las tecnologías y los espacios digitales, pero que lo hace como un complemento de la presencia física en las calles. La protesta se juega cuerpo a cuerpo; se expande y prolonga en el territorio digital.

Imagen 3. Stencil en pared de comuna Santiago Centro, Santiago de Chile

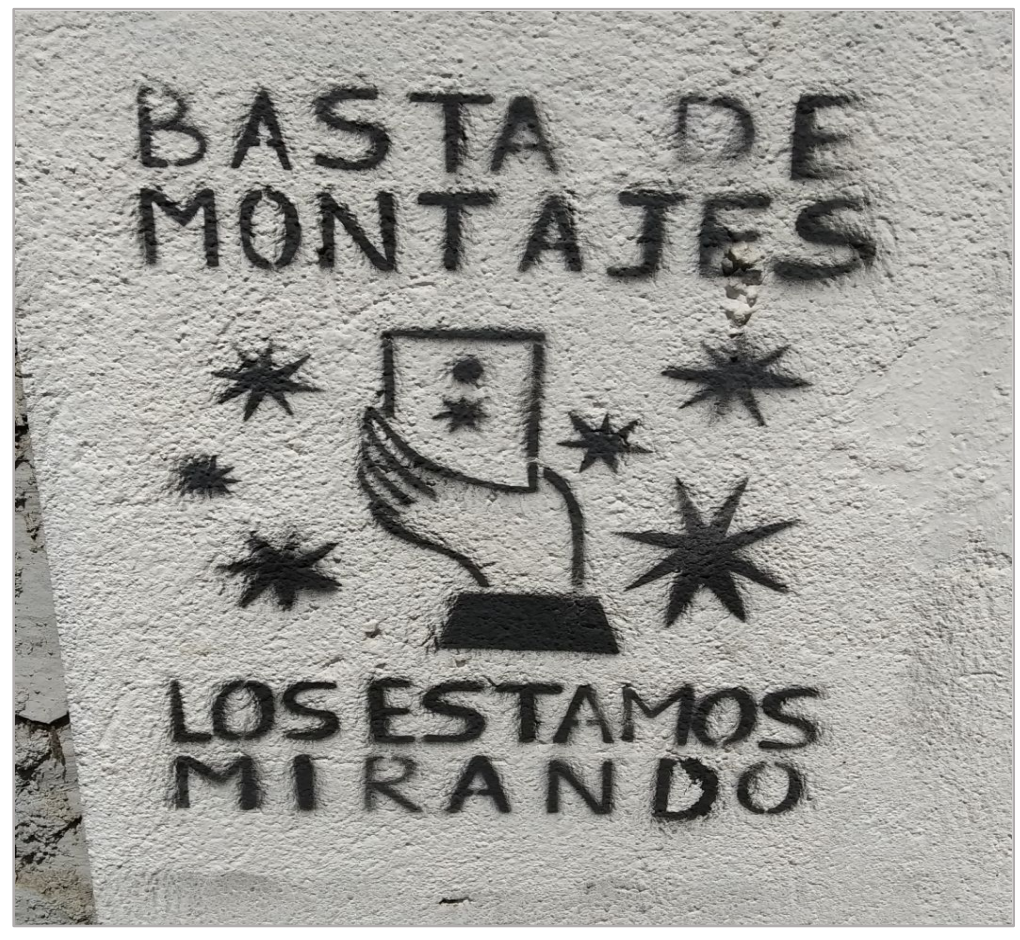

Fuente: Francisco Godinez Galay

Los casos se cuentan por miles. La cuenta de Twitter @ArchivandoChile se dedica a archivar videos y fotos de la protesta, en su mayoría excesos de las fuerzas represivas. Publica en su grupo de Telegram entre 10 y 50 contenidos diarios que envían ciudadanos o que publican en sus cuentas de redes sociales. Los ciudadanos ejercen su actividad de registro de forma individual pero generando un colectivo que se condensa en las redes y en distintas experiencias aglutinantes de difusión alternativa: "La inteligencia colectiva puede verse como una fuente alternativa de poder mediático. Estamos aprendiendo a usar ese poder mediante nuestras interacciones cotidianas en el seno de la cultura de la convergencia" (Jenkins, 2008, p. 15). Casi todos los casos se tratan de registros amateur 
de diferentes sucesos que tienen a los Carabineros ejerciendo la represión, el amedrentamiento, accionando ilegalmente o de forma violenta. Estos registros son hechos muchas veces en condiciones incómodas y tienen valor documental, respaldatorio, donde prima inmortalizar ese momento para hacer creíble la narración.

Imagen 4. Cartuchos de gas lacrimógino

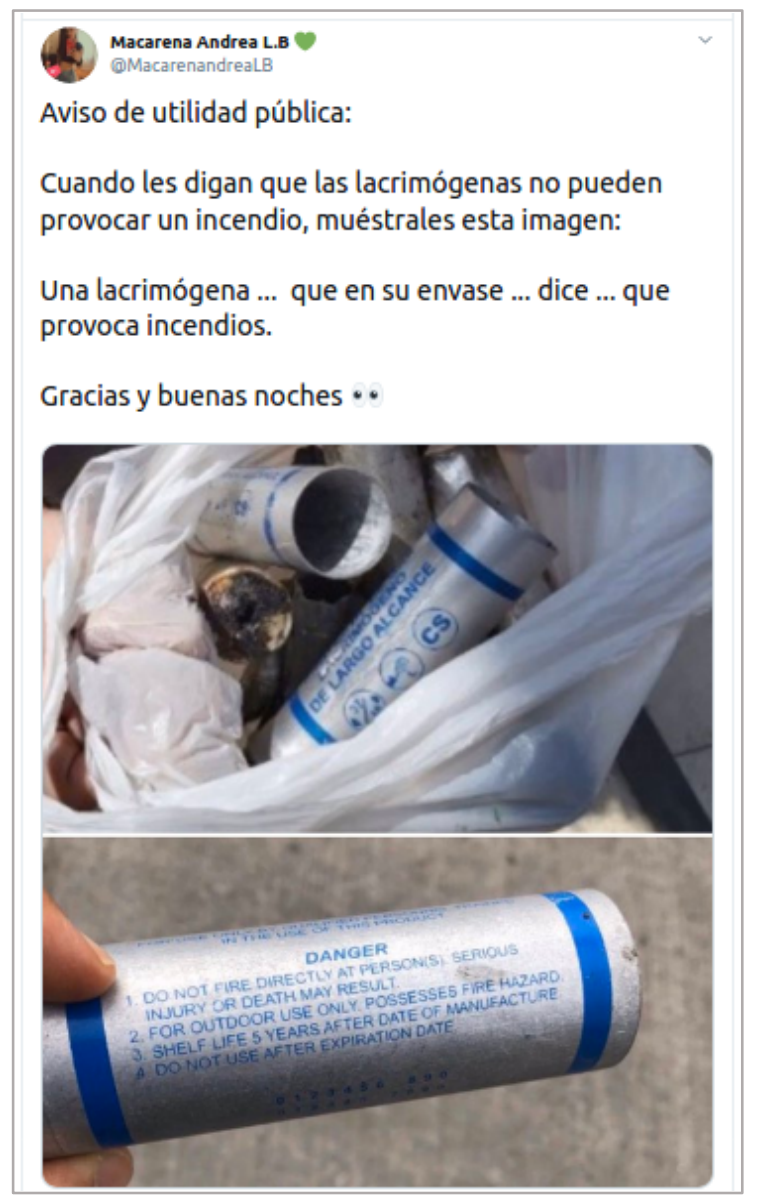

Fuente: https://twitter.com/MacarenandreaLB/status/1210734940800733184/photo/1

Las filmaciones han servido también para revelar montajes de las fuerzas de seguridad intentando inculpar a manifestantes o alimentar el contexto de caos. Es el caso de varios de los incendios y saqueos acaecidos desde el comienzo de la crisis. Con las filmaciones caseras y también algunas cámaras de seguridad se ha podido demostrar cómo Carabineros liberaba lugares para saqueos, o se retiraban de distintos inmuebles minutos antes de incendiarse. O el caso del incendio del día 27 de diciembre de 2019 en el Cine Arte Alameda, lugar paradigmático del arte y que además funcionaba como punto de primeros auxilios en las manifestaciones. La estrategia de inculpar a los 
manifestantes tuvo que dejarse de lado cuando comenzaron a circular filmaciones ciudadanas en las que se veía una bomba lacrimógena lanzada por Carabineros cayendo al techo del cine segundos antes de incendiarse. Posteriormente, las fuerzas policiales intentaron instalar que una bomba lacrimógena no puede provocar un incendio. Nuevamente, fotos tomadas por manifestantes desmontaron esa intención discursiva también y demostraron lo contrario.

Otro caso fue el del atropello de un hincha del club de fútbol Colo Colo. El 28 de enero de 2020, a la salida del estadio, luego de un partido de Colo Colo con Palestino, se enfrentaron hinchas con la policía. Los enfrentamientos no pueden leerse por fuera del contexto de las protestas, puesto que las hinchadas de fútbol ya se habían pronunciado a favor de los reclamos y en contra de que el fútbol continuara (Marcel, 2019). En medio de los enfrentamientos, un camión de caballos de Carabineros acelera de forma imprudente atropellando a un muchacho, que fallecería horas después en el hospital. El video demuestra que el vehículo atropelló a propósito al hincha, y echa por tierra la tesis de la defensa propia. La vocería de Carabineros intentó argumentar que tenía bloqueada la visión porque el parabrisas estaba hecho añicos por pedradas, difundiendo fotos del mismo camión con todo el vidrio astillado. Pero el video tomado por un ciudadano pudo servir para demostrar que al momento de atropellar a la persona, la visión del policía era óptima. Por otra parte, otros hinchas intentaron asistir al atropellado, cosa que fue impedida por la policía que siguió reprimiendo y tirando agua con el carro hidrante mientras los hinchas intentaban avisar que había una persona en grave estado. Esto también fue filmado por los hinchas, y es por eso que puede constatarse que la policía impidió los trabajos de primeros auxilios y resucitación. Asimismo, gran cantidad de otros videos de carabineros atropellando manifestantes o tirándoles el auto o la moto encima, sirvieron para argumentar que no se trataba de un caso aislado sino de una conducta habitual de la policía. ${ }^{2}$

\footnotetext{
${ }^{2}$ Para profundizar en el fenómeno se puede consultar un compilado de registros audiovisuales de Carabineros atropellando adrede a ciudadanos en https://twitter.com/Gabriela0799/status/1222546009487745024
} 
Imagen 5. Denuncia de falta de identificación en Carabineros

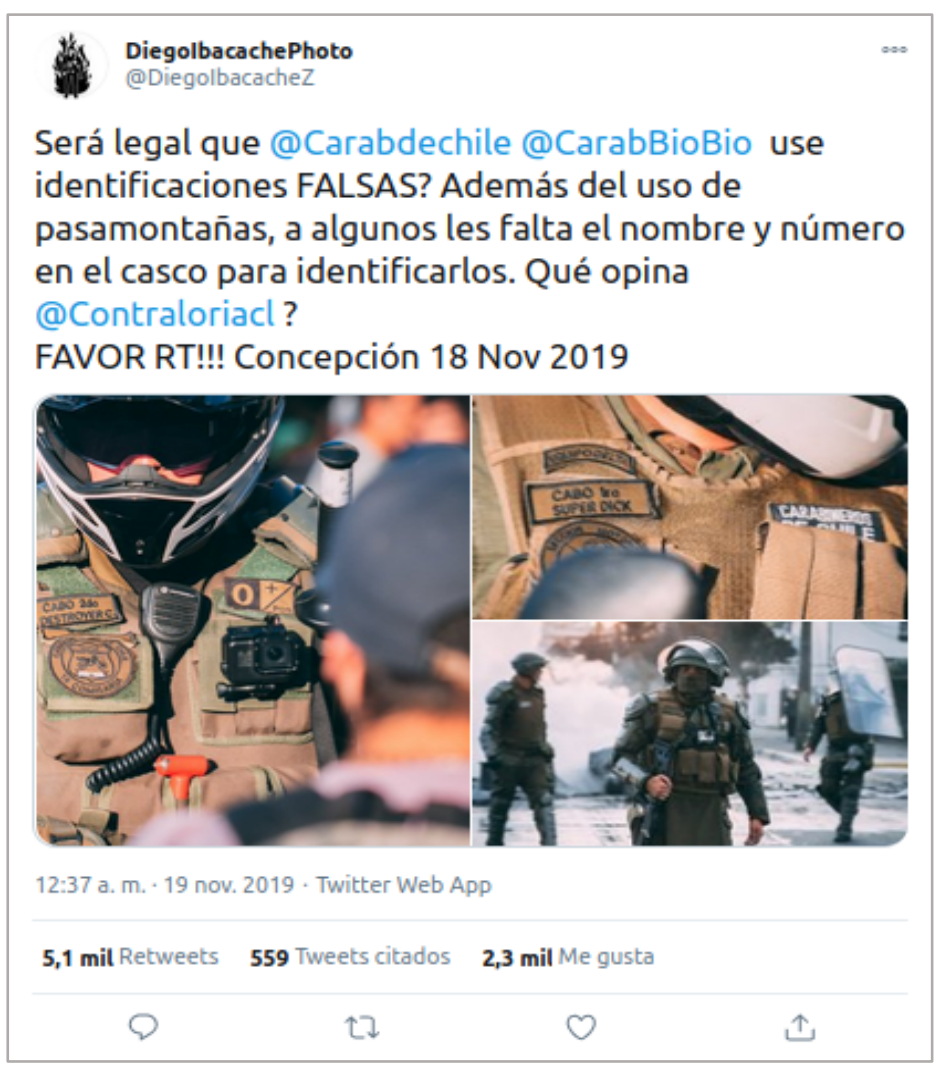

Fuente: https://twitter.com/DiegolbacacheZ/status/1196633655587815425

\subsection{ESPACIOS PÚBLICOS HÍBRIDOS}

El valor de la imagen es de insoslayable protagonismo en las revueltas de Chile. No solo por la importancia de los registros audiovisuales y fotográficos para establecer el relato de las revueltas y contrarrestar el poder narrativo oficial, sino por cómo las ciudades se han impregnado de denuncia y expresión a través de lo visual.

Las paredes funcionan como tecnologías de comunicación, entendiéndolas como "todas aquellas que fueron creadas o empleadas para transmitir mensajes" (Murolo, 2019a, p. 4). Las paredes son un medio porque "es una tecnología que habilita la comunicación [y] es un conjunto de prácticas sociales y culturales que han crecido alrededor de una tecnología" (Varela, 2014, p. 268), convirtiéndose, metafóricamente, en una pantalla más. 
Imagen 6. Pared pintada en las inmediaciones de Plaza Dignidad, Santiago de Chile

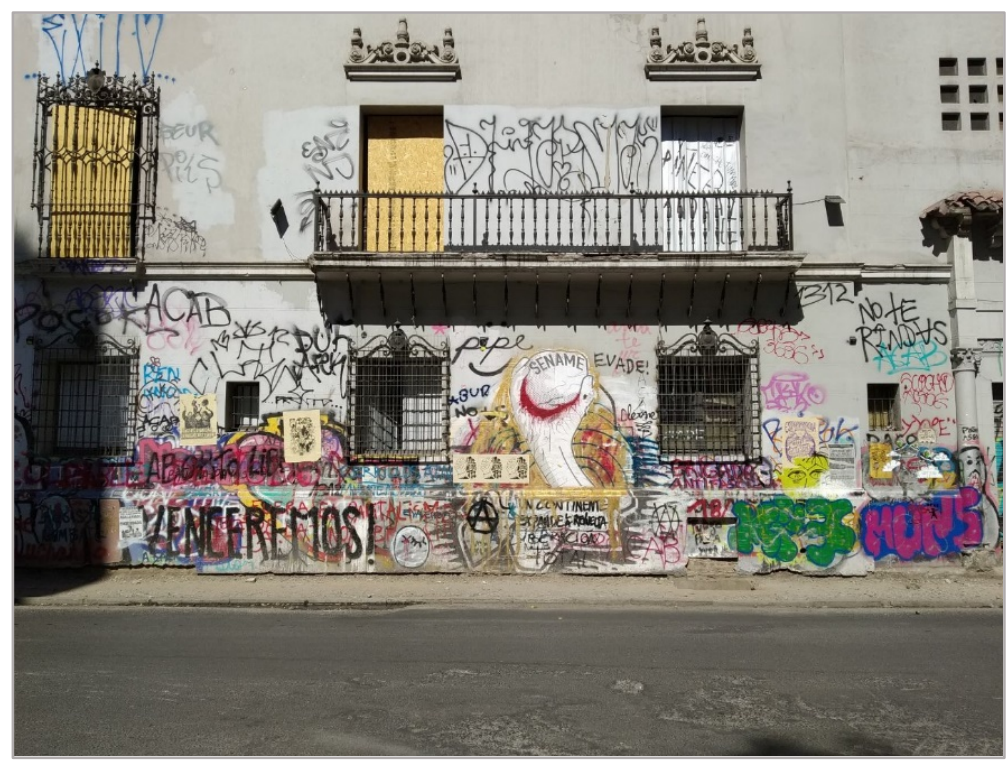

Fuente: Francisco Godinez Galay

La prolongación temporal de la protesta da lugar a que este tipo de expresiones se sofistique. No solo aparecen grafiti intempestivos, sino que comienza a aflorar una poética en los rayados de las paredes, como también una estética visual en pinturas murales, en stenciles, en el adorno o resignificación de monumentos y en la generación de una cartelería (en papel, en tela y en collage).

Imagen 7. Persiana comercial en calle San Isidro, comuna de Santiago de Chile

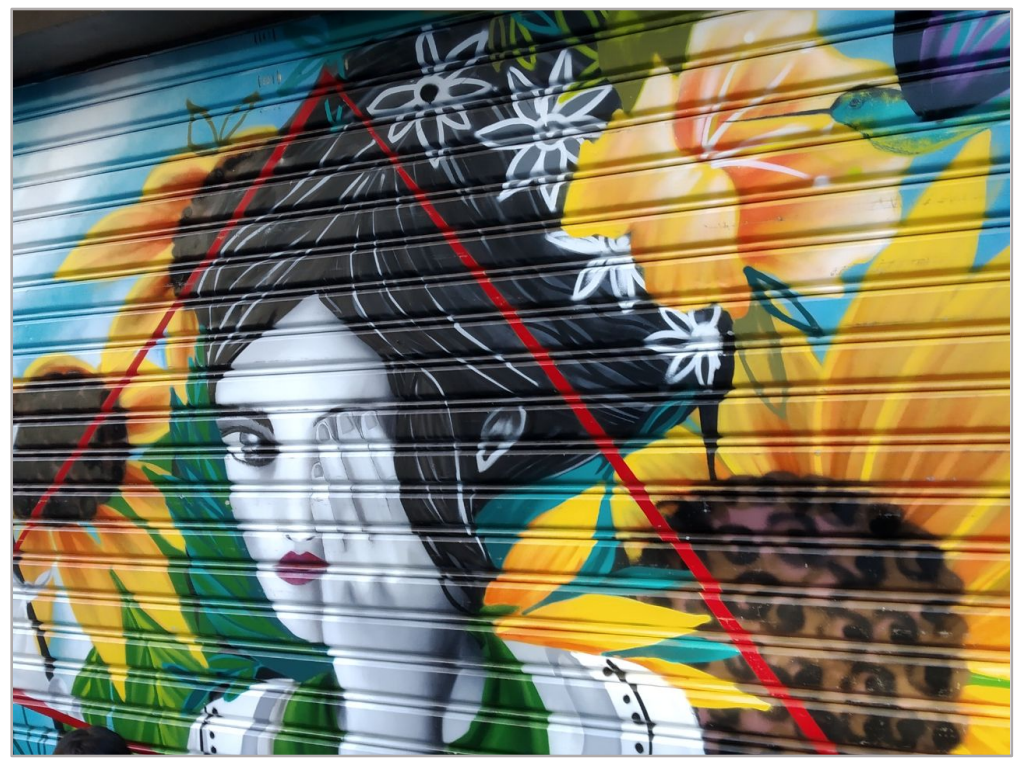

Fuente: Francisco Godinez Galay 
Asimismo, estas imágenes se registran, inmortalizan y reproducen a través de las pantallas de los ciudadanos, posibilitando que esas expresiones no se pierdan aunque sean tapadas. Se envían por WhatsApp y Telegram, se publican en Twitter, en Facebook e Instagram. Tan importante es esta pantalla para editorializar la vida por parte de los manifestantes, que también hay una sorda disputa por ellas. Al cierre de este texto, por ejemplo, la municipalidad de Ñuñoa, en Santiago, le solicitó al Teatro de la Universidad Católica que pinte su fachada, es decir, que tape las frases, dibujos y carteles que los manifestantes han realizado durante más de tres meses. El teatro se negó. Y claro, lo difundió en redes con las pruebas: fotos de la fachada y de la solicitud municipal, obteniendo el apoyo de una gran cantidad de personas.

Imagen 8. Denuncia Teatro UC.

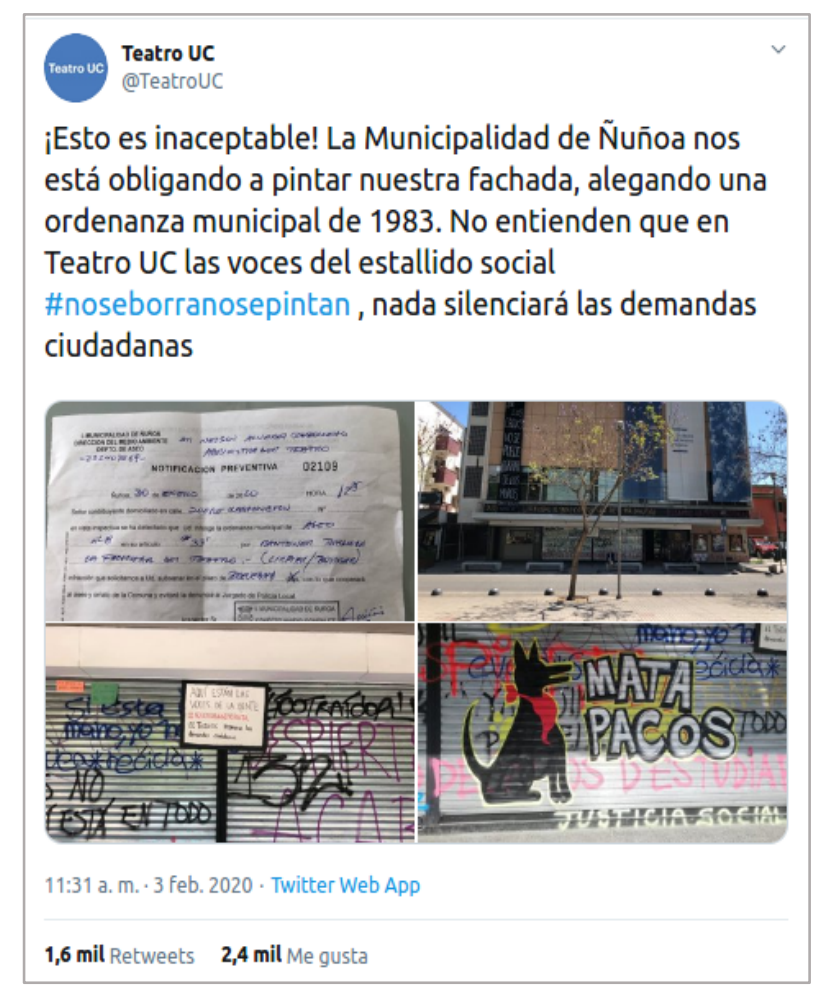

Fuente: https://twitter.com/TeatroUC/status/1224339565571444744

En el abordaje hacia la importancia de la imagen, es elocuente la gran cantidad de mutilados oculares que ha habido desde el comienzo del estallido. Los Carabineros apuntan a los ojos, a la mirada. A pesar de la negativa de Carabineros, videos confirman que los agentes disparan hacia la cabeza, contra todos los protocolos. En menos de dos meses de protestas, más de 350 personas habían sufrido lesiones oculares o pérdida de 
uno o dos ojos por disparos de las fuerzas de seguridad (Navarrete, 2019). La vigilancia ciudadana evidencia los abusos. El tema, a su vez, se ha convertido en protagonista de la cartelería que adorna las paredes y se ha difundido por las redes sociales.

Imagen 9. Afiche pegado en las paredes del centro cultural GAM, en las inmediaciones de la Plaza Dignidad, Santiago de Chile.

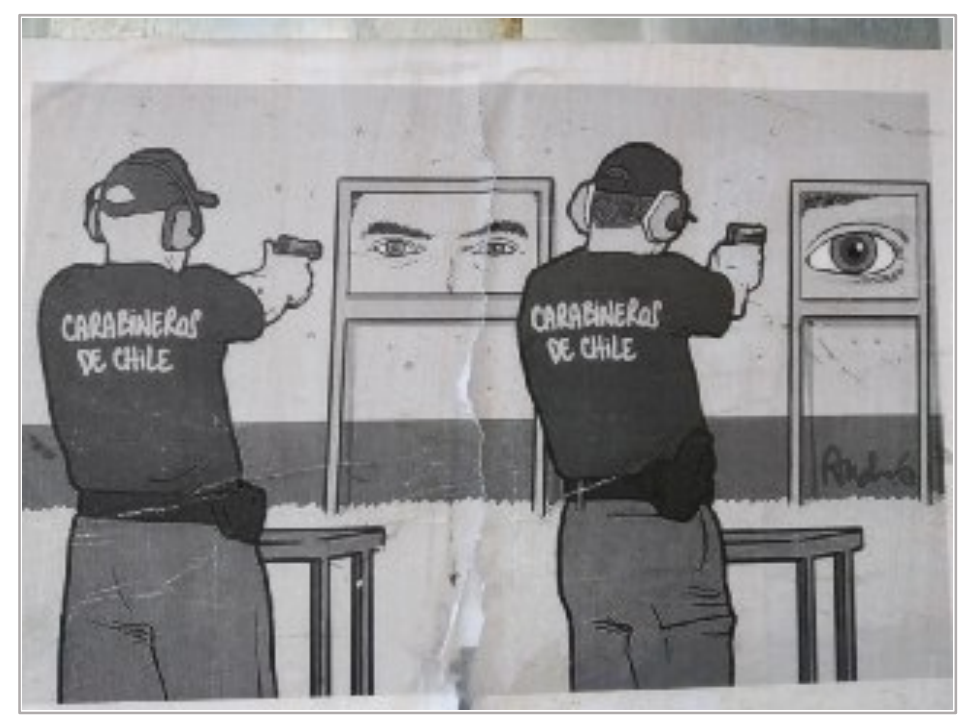

Fuente: Francisco Godinez Galay

Imagen 10. Afiche pegado en las paredes del centro cultural GAM, en las inmediaciones de la Plaza Dignidad, Santiago de Chile.

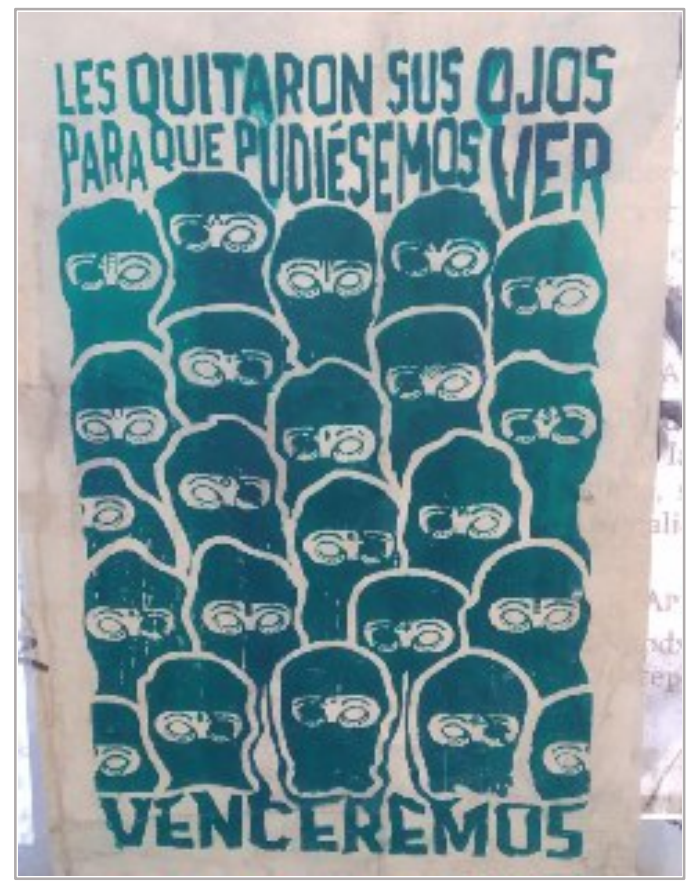

Fuente: Francisco Godinez Galay 


\section{REGISTRO Y CIRCULACIÓN DE DISCURSOS AUDIOVISUALES COMO ESTRATEGIA DE RESISTENCIA Y PRODUCCIÓN DE MEMORIA POPULAR}

Hay dos arenas en apariencia separadas, pero que se confunden y entrelazan: el espacio urbano como eje de las protestas y también de la comunicación, y el territorio digital, espacio de diálogo, de difusión de información, de denuncia, de expresión, donde se depositan los registros de abusos recolectados en la vía pública. Hoy esos territorios parecen resignificarse y hasta encontrarse para generar una nueva forma de entender lo social como una imbricación de constante interacción entre lo digital y lo analógico: "Ya no se puede hablar de una realidad y una virtualidad. Hay una digitalidad que es parte de lo real, cada vez más indisociable, complementaria, fundida, continua" (Godinez Galay, 2017, párr. 4). Los ciudadanos filman, producen, envían, publican, reenvían, reciben, seleccionan, dialogan, consumen. Todo en paralelo y de forma natural. "La distinción entre los medios de comunicación interpersonal y medios de espectáculo e información, se ha vuelto difusa" (Varela, 2014, p. 281).

Un tercer espacio, el de los medios masivos de comunicación, no es una opción para los manifestantes porque están bloqueados y deslegitimados. Es solo una aspiración o demanda: que la TV no mienta más sobre lo que sucede en las calles (Rovira-Sancho, 2013). La protesta, por lo pronto, ocupa los lugares que puede por sus propios medios: las redes y la calle. Los medios alternativos están más cerca de ser parte de la calle que del ámbito de los medios masivos de comunicación. Estos espacios, están desvinculados de lo que relata el discurso de la opinión pública oficial y quedan lejos de la experiencia de la mayoría de la ciudadanía.

Asimismo, esos dispositivos y esa posibilidad de filmar y transmitir audiovisual por mano propia será fundamental para generar el archivo del presente que nos permita entendernos en el futuro. Hay una construcción colectiva de memoria popular y un archivo realizado sin necesidad de conocimientos técnicos, junto con la posibilidad de narrar la propia historia desde los protagonistas. La Historia se hace más compleja, pero no la escriben solo los que tienen acceso a alfabetización y a unos pocos medios técnicos. Hoy los dispositivos de registro y circulación brindan una posibilidad mayor 
que antes para lograr la incidencia de la voz de aquellos a los que siempre les fue difícil, no porque no tuvieran nada que decir, sino porque no tenían las posibilidades materiales de amplificarlo e incidir en lo público.

\section{CONCLUSIONES}

Las protestas ciudadanas en Chile de fines de 2019 que comenzaron con el reclamo por el aumento del pasaje de Metro, lograron impulsar la denuncia pública de desigualdades estructurales y el reclamo por una nueva constitución derivó en la realización de una consulta popular en octubre de 2020, donde la opción "Apruebo redactar una nueva Constitución" ganó con el $78 \%$ de los votos. Si bien las protestas tuvieron un fuerte componente de ocupación del espacio público, incluso con el rebautizo de la Plaza Italia del centro de Santiago de Chile en Plaza Dignidad, las protestas tuvieron lugar en un espacio híbrido con componentes analógicos y digitales, configurado por el uso de pantallas múltiples y la difusión de imágenes a través redes sociales digitales. La protesta comienza en el territorio físico, pero se difunde rápidamente gracias a filmaciones caseras y redes sociales, mutliplicándose la participación a gran velocidad. Los dispositivos y territorios digitales han sido utilizados para la construcción de un relato popular sobre los sucesos que ha logrado contrarrestar a los medios masivos y las voces institucionales.

La respuesta represiva del Estado a través de sus fuerzas de seguridad se enfrentó a un nuevo repertorio de acción colectiva habilitada por nuevas pantallas. La resistencia a la represión a través de la denuncia de los abusos y violaciones de Derechos Humanos por parte de Carabineros a través del registro y divulgación de imágenes de videos de circuitos cerrados de videovigilancia, de teléfonos celulares durante las protestas, y de los espacios públicos híbridos, en los que las expresiones de arte callejero traspasan el margen en el que están inscritos a través de su reproducción digital en redes sociales.

La posibilidad de los y las manifestantes de registrar, publicar y circular imágenes de la represión, se constituyó en un elemento fundamental de las protestas y un respaldo para contrarrestar el discurso oficial muchas veces asentado en los medios masivos de comunicación. La presencia de las cámaras de seguridad y de los teléfonos celulares es 
resignificada por los y las protagonistas de los reclamos y reapropiada con fines de difusión de documentos que han permitido demostrar violaciones a los Derechos Humanos y expandir las causas de los reclamos del territorio físico al digital y viceversa.

Con el correr de las manifestaciones, hemos asistido a la emergencia de una mecánica de la protesta, de una producción audiovisual que la retrata y que la multiplica, que está adherida a la protesta misma como parte imprescindible de ella y que confirma la importancia de la imagen en el contexto de los reclamos.

La imagen se constituye, entonces, como discurso de verdad en la construcción colectiva de una memoria popular de las protestas ciudadanas, arrebatándole a los medios masivos de comunicación el privilegio de nombrar. Así, se retoma la posibilidad de narrar la propia historia desde la perspectiva de los protagonistas, como parte de un relato colectivo presente, pero también construyendo el archivo que se vuelve herramienta de visibilización e identidad. Hoy ciudadanas y ciudadanos tienen la posibilidad de generar pruebas con valor de verdad para resistir el discurso dominante. Lo hacen de una manera improvisada, impulsiva, creativa y exprimiendo las posibilidades de la tecnología y los territorios digitales.

\section{REFERENCIAS BIBLIOGRÁFICAS}

Atria, J. (2019). Evadir impuestos y evadir el metro: desigual impacto social y desigual castigo. En CIPER. 18/10/2019. Recuperado de https://www.ciperchile.cl/2019/10/18/transporte-publico-e-impuestos-desigualdadde-evasiones/

Balsiger, P. y Lambelet, A. (2014). Participant Observation. En D. Della Porta (Ed.), Methodological Practices in Social Movement Research (pp. 144-172). Oxford University Press.

Bellei, C., Contreras, D. y Valenzuela, J. P. (2010). Ecos de la revolución pingüina. Santiago: Editorial Pehuén. 
Binder, I. (2019). Identidad y agencia colectiva del movimiento ciberfeminista en América Latina. El caso de ciberfeministaslatam. Dígitos: Revista de Comunicación Digital. 5, 210-233. Recuperado de http://roderic.uv.es/handle/10550/71392

Benkler, Y. (2006). The wealth of networks: How social production transforms markets and freedom. New Haven: Yale University Press.

Castells, M. (2012). Redes de indignación y esperanza: los movimientos sociales en la era de Internet. Madrid: Alianza.

Cattaneo, E. (2020, marzo 7). La primera línea en las protestas de Chile. La Diaria. Recuperado de https://ladiaria.com.uy/lento/articulo/2020/3/la-primera-linea-en-lasprotestas-de-chile/

CNN Chile (2019a). Piñera: estamos en guerra contra un enemigo poderoso. CNN Chile 21/10/2019. Recuperado de https://www.cnnchile.com/pais/pinera-estamos-enguerra-contra-un-enemigo-poderoso_20191021/

CNN Chile (2019b). Carabineros explica por qué funcionarios usaron apodos en el uniforme en Concepción. CNN Chile 25/11/2019 Recuperado de https://www.cnnchile.com/pais/carabineros-explica-por-que-funcionarios-usaronapodos-en-el-uniforme-en-concepcion_20191125/

Constitución Política de la República de Chile (actualizado a 2010)

De Certeau, M. (1996). Invención de lo cotidiano. I. Artes de hacer. México: Universidad Iberoamericana.

Della Porta, D. (2014). Social Movement Studies and Methodological Pluralism: An Introduction. En D. Della Porta Methodological Practices in Social Movement Research (pp. 1-20). Oxford University Press.

Deleuze, G. (2006). Post-scriptum sobre las sociedades de control. Polis, 13. Recuperado de http://journals.openedition.org/polis/5509 
Doueihi, M. (2010). La gran conversión digital. Buenos Aires: Fondo de Cultura Económica.

El Siglo. (2020, octubre 10). El prontuario de Carabineros. El Siglo.

https://elsiglo.cl/2020/10/10/el-prontuario-de-carabineros/

Fernández Prados, J. S. (2012). Ciberactivismo: conceptualización, hipótesis y medida. ARBOR Ciencia Pensamiento y Cultura, 188-756, julio-agosto 2012. Recuperado de http://arbor.revistas.csic.es/index.php/arbor/article/view/1490/1500

Flesher Fominaya, C. (2014). Social Movements and Globalization: How Protests, Occupations and Uprisings are Changing the World. Houndmills: Palgrave Macmillan.

Fominaya, C. F. (2015). Debunking Spontaneity: Spain's 15-M/Indignados as Autonomous Movement. Social Movement Studies, 14(2), 142-163. https://doi.org/10.1080/14742837.2014.945075

Gargarella, R. (2020, febrero 10). Diez puntos sobre el cambio constitucional en Chile. Nueva Sociedad. Recuperado de https://nuso.org/articulo/diez-puntos-sobre-elcambio-constitucional-en-chile/

Garrett, R. Kelly y Edwards, P. N. (2007). Revolutionary Secrets: Technology's Role in the South African Anti-Apartheid Movement. Social Science Computer Review, 25, 1326.

Godinez Galay, F. (2017). El amor en los tiempos transmedia. Blog Fancisco Godinez Galay. 19 de agosto de 2017. Recuperado de https://franciscogodinezgalay.wordpress.com/2017/08/19/el-amor-en-los-tiempostransmedia/

GSM Association. (2019). La economía móvil en América Latina 2019. GSMA. Recuperado de https://www.gsma.com/mobileeconomy/wpcontent/uploads/2020/03/GSMA_MobileEconomy2020_LATAM_Esp.pdf 
Instituto Nacional de Derechos Humanos (2020). Informe anual Situación de los Derechos Humanos en Chile (p. 109). INDH.

Jenkins, H. (2008). Introducción: Adoración en el altar de la convergencia: un nuevo paradigma para comprender el cambio mediático. Convergence Culture. La cultura de la convergencia de los medios de comunicación. Barcelona: Paidós.

Jurgenson, N. (2012). When Atoms Meet Bits: Social Media, the Mobile Web and Augmented Revolution. Future Internet, 4(1), 83-91.

https://doi.org/10.3390/fi4010083

Liu, J. (2015). Communicating beyond Information? Mobile Phones and Mobilization to Offline Protests in China. Television \& New Media, 16(6), 503-520.

https://doi.org/10.1177/1527476414544972

Manacorda, M. y Tesei, A. (2020). Liberation Technology: Mobile Phones and Political Mobilization in Africa. Econometrica, 88(2), 533-567.

https://doi.org/10.3982/ECTA14392

Mayol Miranda, A. y Azócar Rosenkranz, C. (2011). Politización del malestar, movilización social y transformación ideológica: El caso “Chile 2011". Polis. Revista Latinoamericana, 30. Recuperado de https://journals.openedition.org/polis/2218 Marcel, S. (2019). La vuelta del fútbol en duda: 16 hinchadas se oponen a la vuelta del Campeonato Nacional y anuncian boicot. Dale Albo. 9/11/2019. Recuperado de https://dalealbo.cl/colocolo/La-vuelta-del-futbol-en-duda-16-hinchadas-se-oponen-ala-vuelta-del-Campeonato-Nacional-y-anuncian-boicot-20191109-0005.html

Monterde, A. y Postill, J. (2014). Mobile ensembles: The uses of mobile phones for social protest by Spain's indignados. Routledge companion to mobile media.

Morales Morante, L. (2011). La producción de ficción para telefonía móvil. TELOS. Cuadernos de Comunicación e Innovación. Recuperado de http://sociedadinformacion.fundacion.telefonica.com/url-direct/pdfgenerator?tipoContenido=articuloTelos\&idContenido=2011050914020001\&idioma=es 
Mosca, L. (2008). A Double-Faced Medium? The Challenges and Opportunities of the Internet for Social Movements. EUI Working Papers MWP 2007/23.

Morozov, E. (2011). The Net Delusion. The Dark Side of Internet Freedom. New York: Public Affairs.

Mosca, L. (2008). A Double-Faced Medium? The Challenges and Opportunities of the Internet for Social Movements. EUI Working Papers MWP 2007/23.

Murolo, L. (2019a). Clase 1. Nuevas pantallas. Maestría en Industrias Culturales. Universidad Nacional de Quilmes.

Murolo, L. (2019b). Clase 7. Nuevas pantallas. Maestría en Industrias Culturales. Universidad Nacional de Quilmes.

Navarrete, J. (2019). INDH actualiza reporte y cifra en 352 las víctimas con heridas oculares en protestas. La Tercera, 7 de diciembre de 2019. Recuperado de https://www.latercera.com/nacional/noticia/indh-actualiza-reporte-cifra-352-lasvictimas-heridas-oculares-protestas/930024/

Neumayer, C. y Stald, G. (2014). The mobile phone in street protest: Texting, tweeting, tracking, and tracing. Mobile Media \& Communication, 2(2), 117-133.

https://doi.org/10.1177/2050157913513255

Noble, S. U. (2018). Algorithms of oppression: How search engines reinforce racism. NYU Press.

O’Neil, C. (2018). Armas de destrucción matemática: Cómo el big data aumenta la desigualdad y amenaza la democracia. Madrid: Capitán Swing Libros.

Pariser, E. (2011). The Filter Bubble: What the Internet is hiding from you. London: Penguin UK.

Parra, J. (2018). Aparece Chile: estos son los 10 países más desiguales del mundo. Bío Bío Chile. 4 de julio de 2018. Recuperado de 
https://www.biobiochile.cl/noticias/nacional/chile/2018/07/04/aparece-chile-estosson-los-10-paises-mas-desiguales-del-mundo.shtml

Prieto Castillo, D. (1984). Discurso autoritario y comunicación alternativa. México DF: Premia Editora.

Ravanal, L. y Marfn, F. (2020). Human Rights Violations Committed in Chile After the Social Outburst of 18-O. Medicine and Law, 39, 1.

Rheingold, H. (2002). Smart mobs: The new social revolution. Perseus Publishing.

Rheingold, H. (2008). Mobile Media and Political Collective Action. En J. E. Katz (Ed.), Handbook of mobile communication studies (pp. 225-239). Cambridge, MA: MIT Press.

Rovira-Sancho, G. (2013). Activismo mediático y criminalización de la protesta: medios y movimientos sociales en México. Convergencia, 20(61). Recuperado de http://www.scielo.org.mx/scielo.php?pid=S140514352013000100002\&script=sci_arttext

Salazar Vergara, G. (2019, octubre 24). El «reventón social» en Chile Una mirada histórica. Nueva Sociedad. Recuperado de https://nuso.org/articulo/protestas-Chileestudiantes-neoliberalismo/

Sehnbruch, K. y Donoso, S. (2020). Social Protests in Chile: Inequalities and other Inconvenient Truths about Latin America's Poster Child. Global Labour Journal, 11(1). https://doi.org/10.15173/glj.v11i1.4217

Shirky, C. (2008). Come on Everybody. The Power of Organizing Without Organizations. Nueva York: Penguin Group.

Silverstone, R., Hirsch, E. y Morley, D. (1996) Tecnologías de la información y de la comunicación y la economía moral de la familia. En R. Silverstone y E. Hirsch (Eds.), Los efectos de la nueva comunicación. El consumo de la moderna tecnología en el hogar y en la familia. Barcelona: Bosch. 
Suárez, S. L. (2006). Mobile Democracy: Text Messages, voter turnout and the 2004 Spanish General Election. Representation, 42(2), 117-128.

https://doi.org/10.1080/00344890600736358

Suárez Bonilla, S. (s/a). Gramáticas audiovisuales para plataformas celulares. Scoop.it. Recuperado de http://www.scoop.it/t/maestr-s-y-redes-deaprendizaje/p/1273455584/gramaticas-audiovisuales-para-plataformas-celularessofia-suarez

Suárez Jaramillo, A. (2019). ¿¿De dónde viene el milagro fallido de Chile? France 24. 30/10/2019. Recuperado de https://www.france24.com/es/20191030-historiamilagro-fallido-chile-desigualdad

Subtel. (2019, octubre 18). Usuarios de Internet móvil consumen 10 GB en promedio al mes y número de teléfonos móviles sube a 26 millones. Subsecretaría de Telecomunicaciones de Chile. Recuperado de https://www.subtel.gob.cl/usuarios-deinternet-movil-consumen-10-gb-en-promedio-al-mes-y-numero-de-telefonos-movilessube-a-26-millones/

Tilly, C. y Wood, L. (2010). Los Movimientos Sociales, 1768-2008: Desde sus Orígenes a Facebook. Barcelona: Crítica.

Telam (2019). Piñera: los videos de la represión "son falsos o tergiversados". 26/12/2019. Recuperado de https://www.telam.com.ar/notas/201912/419250-pinerachile-protestas-videos-falsos-tergiversados-carabineros-represion.html Vargas, D. (2019, octubre 15). "Evadir no pagar, otra forma de luchar": Estudiantes secundarios realizan masivos actos de evasión en el Metro. La Izquierda Diario. Recuperado de http://www.izquierdadiario.es/Evadir-no-pagar-otra-forma-de-lucharestudiantes-secundarios-realizan-masivos-actos-de-evasion-en

Varela, M. (2014). Él miraba televisión, youtube. La dinámica del cambio en los medios. En M. Carlón y C. A. Scolari (Eds.), El fin de los medios masivos. Buenos Aires: La Crujía. 
Williams, R. (1992). Historia de la comunicación. Vol. II. De la imprenta a nuestros días. Barcelona: Editorial Bosch.

Williams, R. (2011). Televisión. Tecnología y forma cultural. Buenos Aires: Paidós.

Yates, L. (2015). Rethinking prefiguration: Alternatives, micropolitics and goals in social movements. Social Movement Studies, 14(1), pp. 1-21.

https://doi.org/10.1080/14742837.2013.870883

Zuboff, S. (2019). The Age of Surveillance Capitalism: The Fight for a Human Future at the New Frontier of Power: Barack Obama's Books of 2019. London: Profile Books. 